\title{
A RELAÇÃO CAMPO-CIDADE NO MUNICÍPIO DE FRANCISCO BELTRÃO - PARANÁ - BRASIL
}

\author{
LA RELACIÓN CAMPO-CIUDAD EN LA MUNICIPALIDAD DE FRANCISCO \\ BELTRAO - PARANA - BRASIL
}

\author{
THE RELATIONSHIP COUNTRY-CITY IN THE MUNICIPALITY OF \\ FRANCISCO BELTRÃO - PARANÁ - BRAZIL
}

\author{
Marcos Leandro Mondardo \\ Universidade Federal da Grande Dourados - UFGD. \\ marcosmondardo@yahoo.com.br
}

\section{Resumo}

A relação campo-cidade foi historicamente determinada pelos modelos econômicos implementados. No Brasil, essa relação ocorreu segundo modificações econômicas que refletiram e materializaram os modos de vida dos habitantes desses espaços. Neste contexto, este artigo apresenta-se como uma contribuição no intuito de analisar e refletir sobre alguns aspectos da relação campo-cidade, em especial no município de Francisco Beltrão, localizado no Sudoeste do estado do Paraná - Brasil. O município tem sua relação campo-cidade "incipiente" no período entre 1850 e 1940, em que predomina uma economia "cabocla" voltada à subsistência. A partir de 1950, ocorre uma migração para o município de Francisco Beltrão, oriunda do Rio Grande do Sul e de Santa Catarina que alavanca e intensifica o relacionamento entre campo-cidade. A partir de 1970, surgem novos elementos no campo e na cidade que transformam e modificam a relação entre esses dois espaços. Atualmente, a relação campo-cidade se dinamiza, pela industrialização e, assim, terceirização do campo e pelo aumento populacional e de empresas com sedes na cidade vinculadas ao campo.

Palavras-chave: caboclos, migração, modernização agrícola, industrialização, complexificação.

\section{Resumen}

La relación de la campo-ciudad fue historicamente determinó por los modelos económicos aplicados. En Brasil, esa relación ocurrió segundas modificaciones económicas que reflejaron y los estilos de vida se realizaron de los habitantes de esos espacios. En este contexto, este artículo se presenta como una contribución en el diseño de analiza y refleja algunos aspectos de la campo-ciudad de la relación, en especial en la municipalidad de Francisco Beltrão, localizado en el Suroeste del estado del Paraná Brasil. La municipalidad tiene su relación campo-ciudad "incipiente" en el período de 1850 a 1940, en que predomina una economía mestiza por la subsistencia. De 1950, ocurre una migración para la municipalidad de Francisco Beltrão, surgiendo de Rio Grande do Sul y de Santa Catarina esa palanca e intensifica la relación entre la campo- 
ciudad. De 1970, los elementos de noticias surgen en el campo y en la ciudad que se transforma y modifica la relación entre esos dos espacios. En la actualidad, la relación campo-ciudad es motivada por la industrialización y recurriendo afuera así, del campo $\mathrm{y}$, por el aumento de la población y de compañías ligadas al campo con la sede en la ciudad.

Palabras clave: mestizo, la migración, la modernización agrícola, la industrialización, complexificação.

\begin{abstract}
The country-city relationship was historically determined by the economic models implemented. In Brazil, that relationship has occurred according economic changes that, at the same time, reflected and materialized the ways of life of the inhabitants of those spaces. In this context, this article intends to be a contribution to the analysis and reflection of the country-city relation, in special in the municipality of Francisco Beltrão, located in the Southwest of the state of the Paraná - Brazil. This municipality had the country-city relation "incipient" in 1850 by 1940 period, when dominated a "mestizo" subsistence economy. From 1950, occured a migration to the town of Francisco Beltrão originated from Rio Grande do Sul and Santa Catarina that levered and intensified the relationship between the country and the city. From 1970, new elements arose in the country and in the city that transform and modify the relation between these two spaces. Today, the country-city relation is motivated by the industrialization and the outsourcing from the country producers, by the population increasing and by companies that have their headquarters in the city and are linked to the country.
\end{abstract}

Keywords: mestizo, migration, agricultural modernization, industrialization, complexity. 


\section{Considerações Iniciais}

A oposição entre a cidade e o campo surge com a passagem da barbárie à civilização, da organização tribal ao Estado, do provincialismo à nação, e persiste através de toda a história da civilização até os nossos dias (...). A existência da cidade implica imediatamente a necessidade da administração, da polícia, dos impostos, etc., numa palavra, a necessidade da organização comunitária, partindo da política em geral. É aí que aparece em primeiro lugar a divisão da população em duas grandes classes, divisão essa que repousa diretamente na divisão do trabalho e nos instrumentos de produção. A cidade é o resultado da concentração da população, dos instrumentos de produção, do capital, dos prazeres e das necessidades, ao passo que o campo põe em evidência o fato oposto, o-isolamento - e a dispersão. A oposição entre a cidade e o campo só pode existir no quadro da propriedade privada; é a mais flagrante expressão da subordinação do indivíduo à divisão do trabalho, da subordinação a uma atividade determinada que lhe é imposta. Esta subordinação faz de um habitante um animal da cidade ou um animal do campo, tão limitados um como o outro, e faz renascer todos os dias a oposição entre os interesses das duas partes. O trabalho é ainda o mais importante poder sobre os individuos, e enquanto este poder existir haverá sempre uma propriedade privada.

A ideologia alemã Karl Marx e Friedrich Engels

Observando o espaço geográfico e sua constante re-produção podemos visualizar as formas sensiveis como as edificações residenciais, industriais, comerciais, etc., observando as áreas de cultivo de cereais ou de criação de animais, o fluxo de pessoas se movimentando pelas ruas em determinados horários do dia, não conseguiremos perceber o caráter recorrente das relações entre as pessoas que ocupam o espaço, tanto no campo quanto na cidade. Neste sentido, o campo não está isolado da cidade, haja vista a circulação de pessoas, mercadorias, informações e idéias que as estradas, o comércio, a indústria, as redes de telecomunicação, dentre outras formas de conexão, permitem, assim, relações dialéticas entre campo e cidade. São relações que se complementam, que se interpenetram, que se ligam demonstrando as imbricações entre as relações do vivido, dos homens e mulheres e seu(s) espaço(s), portanto, dos próprios espaços produzidos: campo e cidade.

Neste contexto, o objetivo deste artigo é entender como ocorrem as transformações nas relações entre os homens que vivem no e do campo e, os que vivem na e da cidade, e como tal processo se desdobra no espaço geográfico, tendo especialmente como recorte espacial para a presente reflexão, o município de Francisco Beltrão, localizado no Sudoeste do Paraná (figura 1). 
Objetivamos de modo especial, analisar as redes de comunicação (principalmente de comercialização, de circulação de mercadorias) e as redes de informação (incluso o controle que o Estado exerce sobre o espaço) que "agenciam" as relações campo-cidade e transformam o espaço geográfico, desde a década de 1940, quando o município começou a ser colonizado. Buscaremos abordar, o que cremos ser um importante fundamento para as relações campo-cidade, ou seja: os fatores econômicos e políticos.

Assim, entendemos que o estudo das relações campo-cidade no município de Francisco Beltrão é de grande importância para conhecermos a trama entre as forças e os atores que produzem e transformam estes complexos espaços. Para isso, ensejamos refletir sobre as condições historicamente criadas e as formas de relacionamento estabelecidas entre campo e cidade no município de Francisco Beltrão, Paraná.

\section{Relação Campo-Cidade: Discussões e Contribuições para o Estudo}

Segundo Corrêa (1989:21), as relações campo-cidade ao longo da história, têm sido estudadas por historiadores, antropólogos, sociólogos, economistas e geógrafos, porém, cada área da ciência com o seu objetivo. Pode-se verificar que a diversidade de contribuições direcionadas ao estudo da relação campo-cidade, rural-urbano não se esgotou e tampouco há um consenso entre os pesquisadores do tema.

Neste sentido, um bom apoio para abordar a problemática das relações campocidade, encontra-se no estudo de Marx e Engels (1998:11). Em A ideologia alemã, estes autores analisam esta questão a partir da relação social de produção existente. Consideraram a divisão social do trabalho em que existe a separação do trabalho industrial e comercial de um lado (na cidade) e do outro, o trabalho agrícola (no campo). Estes autores entenderam que esta relação é marcada pela oposição de interesses das classes sociais que vivem no campo com as que vivem na cidade.

Marx (2002:26), no livro primeiro de $O$ capital, entende que nas relações campo-cidade, o campo se torna fonte de matéria-prima para indústria, em geral localizada na cidade (cita o caso da lã de ovelha usada na indústria têxtil na Inglaterra), além de liberar grandes contingentes de camponeses que, ao serem separados da terra e dos seus instrumentos de trabalho, são lançados às cidades para constituírem a mão-deobra, a "força de trabalho" utilizada na indústria. 
Assim, a idéia de uma oposição entre campo e cidade é demonstrada na análise feita por Marx. Nesta perspectiva, foram colocadas como distintas essas duas realidades, a fim de explicar as diferentes classes sociais e as contradições no interior destas. De acordo com Corrêa (1989:25), a oposição entre o rural e o urbano representava nesse período as classes sociais que contribuíam ou se opunham ao capitalismo.

Kautsky (1986:42), em A questão agrária, ao analisar a inserção do modo capitalista de produção na agricultura, entende que o camponês torna-se subordinado a uma burguesia citadina, pois a agricultura passa a depender de insumos adquiridos na cidade (adubos, sementes, rações, etc.), além do crédito hipotecário, que permite a exploração do camponês pelo capitalista financeiro. Este autor entende que a relação campo-cidade é desfavorável aos camponeses ao torná-los dependentes e submissos aos comerciantes, industriais, bancários etc., que vivem na cidade.

Lefébvre (2004:57), em $O$ direito à cidade, entende que ao longo do tempo histórico a relação campo-cidade mudou e, que, a partir da década de 1960, quando o autor realizou parte de seus estudos, a cidade havia se tornado um centro de decisão com comando de uma maior gama de atividades do campo. Desse modo, essas transformações desencadearam um processo de exploração mais sutil, pelas classes citadinas, das classes que vivem no campo, pois, "seja o que for, a cidade em expansão ataca o campo, corrói-o, dissolve-o" (LEFEBVRE, 2004:69).

Contudo, diferentemente das idéias defendidas por estes autores clássicos, entendemos que o campo não deve ser visto como resquício em vias de desaparecimento e, nem a cidade é o lócus do moderno como aponta (em certa medida) Lefébvre (2004); nem que os interesses do campo e da cidade são de oposição, como demonstrou Marx e Engels (1998); e, nem como Kautsky (1986) reitera a brutal submissão do camponês às organizações (comerciais, financeiras etc.) da cidade. Ambos espaços devem ser apreendidos numa visão dialética, haja vista que cada um tem suas especificidades. Além disso, o campo não é sinônimo de rural e tampouco a cidade abarca apenas o urbano. O rural e o urbano expressam o modo de vida e os valores, enquanto o campo e a cidade correspondem à materialização desses modos de vida. Portanto, os valores urbanos estão presentes no campo, assim como também encontramos os valores rurais na cidade.

No entanto, com o avanço do processo de globalização, novas mudanças se processaram (e se processam constantemente) implicando novas relações campo-cidade, marcadas pelo desenvolvimento dos meios de transporte e comunicação, bem como pelo 
crescimento das atividades e rendas não agrícolas entre os residentes rurais. A técnica, a ciência e a informação são peças-chaves do período atual, funcionando como fundamentos da competição entre os lugares (SANTOS, 1997:53-54).

Neste contexto, Silva (1998:51), defende que o campo e a cidade são territórios econômicos-políticos, interdependentes e articulados. Parece redundante, mas, no período contemporâneo não se pode considerar o campo e a cidade dois mundos separados, antagônicos, já que estamos num mundo de relações de complexidade e diversidade, assim, é difícil delimitar com precisão onde começa o campo e termina a cidade e vice-versa. Como afirma Bagli (2004:78), o campo e a cidade não são dois pólos extremos, mas construções humanas permeadas de contradições e especificidades, vinculadas ao seu uso, a sua apropriação e dominação.

Isso leva a refletir que a cidade e o campo são construções socioespaciais, que devem ser analisadas e fortalecidas por suas peculiaridades e singularidades. Ambos não são semelhantes e não podem ser compreendidos como regidos pela mesma lógica, pois no urbano, o artificial e a velocidade dos acontecimentos se processam num tempo rápido. No campo, o tempo é mais lento, as relações sociais estão mais centradas na proximidade, no cotidiano e num maior contato com a natureza. Alentejano (2003:56), relata que no campo a relação com a terra é uma das principais características.

A partir disso, consideramos o campo e a cidade como construções socioespaciais distintas, mas não dicotômicas. A visão setorial-agrícola que perdura nos projetos de desenvolvimento rural acaba por negar o dinamismo e a multiplicidades de funções, dimensões e atividades desenvolvidas no campo. As políticas de desenvolvimento rural necessitam de uma visão dialética e abrangente que incorpore as potencialidades e os atores sociais presentes tanto no campo como na cidade. O local ou regional, por sua vez, permite o encontro dos dois espaços (campo-cidade) como explicita Wanderley (2001:12) ao afirmar que: “(...) nele, as particularidades de cada um não são anuladas, ao contrário são a fonte de integração e da cooperação, tanto quanto das tensões e dos conflitos".

\section{O Período de Ocupação "Cabocla" e a Relação Campo-Cidade no Município de Francisco Beltrão - Sudoeste do Paraná - Brasil (1900 - 1940)}

O território do Sudoeste do Paraná - onde se localiza o município de Francisco Beltrão - era um "imenso vazio demográfico" no início do século $\mathrm{XX}$, de acordo com 
Wachowicz (1985:65). Sua população atingia apenas 3.000 habitantes e era constituída por antigos "peões" de fazendas do município de Palmas no Paraná e de alguns refugiados da justiça, dos Estados de Santa Catarina e Rio Grande do Sul.

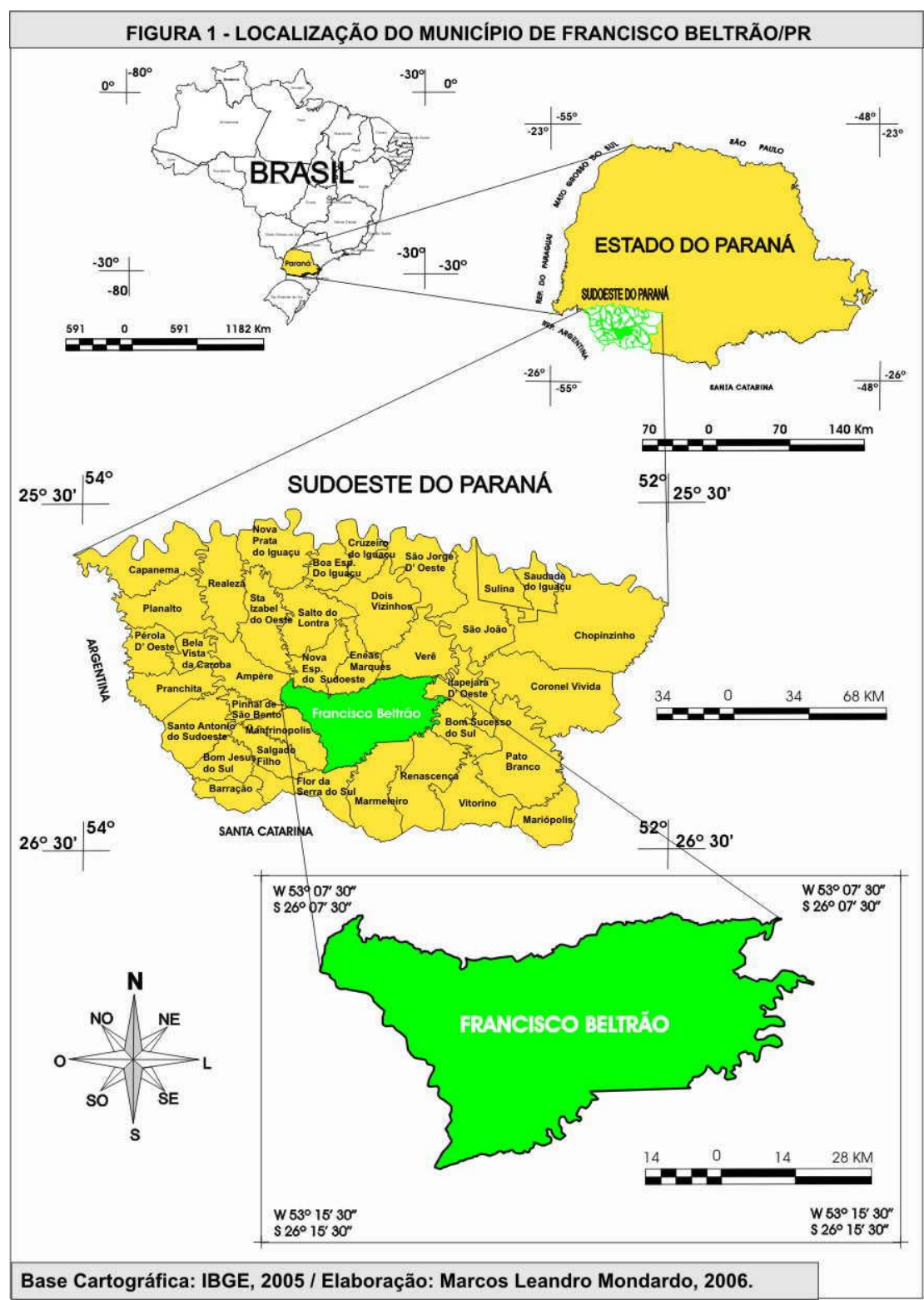


Para Corrêa (1970a:87), “o Sudoeste paranaense foi habitado, antes da vinda dos colonos, por uma população de origem luso-brasileira que se dedicava a algumas atividades extensivas". De acordo com o autor, esses "pioneiros anônimos" foram conhecidos genericamente como caboclos $^{1}$ pela população de migrantes gaúchos e catarinenses que, posteriormente, chegaram e ocuparam o território ${ }^{2}$.

De acordo com Steca e Flores (2002:30), no ano de 1858, já existiam no território do Sudoeste do Paraná "caboclos e alguns estrangeiros aculturados, os quais pouco faziam além de prover às suas próprias necessidades imediatas. Faltavam meios de transporte e de comunicação com o mundo exterior".

Para Padis (1981:147), a primeira iniciativa de povoamento do território do Sudoeste paranaense se deu por volta de 1878, através da iniciativa governamental, com a criação de 18 núcleos populacionais, quando se tentou povoar regiões próximas ao município de Guarapuava.

Este povoamento, decorrente de ações dos governos estaduais e federais, para Souza (1980:61), visava firmar a posse territorial da Sudoeste do Paraná. Neste período (1900 a 1940), desenvolveu-se aí uma economia madeireira complementada por uma pecuária extensiva e a extração da erva-mate. Contudo, estas atividades, por sua própria natureza, não favoreciam o aumento rápido da densidade populacional. Além disso, faltavam transportes e comunicação com outros territórios.

Portanto, até o inicio de 1940, a ocupação territorial foi "incipiente", resultante do grande isolamento em que o território se encontrava. Esta permaneceu praticamente estagnada e sua economia se restringia, praticamente, à subsistência.

Neste contexto, a área onde se desenvolveu o povoado denominado de "Vila Marrecas" - que posteriormente em 1952 se tornou município e passou a se chamar oficialmente de Francisco Beltrão - foi ocupada "efetivamente" a partir do final da década de 1940, quando o então Presidente da República Getúlio Vargas criou a CANGO - Colônia Agrícola Nacional General Osório, com objetivo de colonizar o Sudoeste do Paraná. Para isso incentivou-se a vinda de agricultores oriundos, sobretudo,

\footnotetext{
${ }^{1}$ Segundo Wachowicz (1987:85), o caboclo do Sudoeste paranaense não precisava ser necessariamente descendente do índio. Para o indivíduo ser classificado como caboclo, precisava ter sido apenas criado no sertão, portanto, na floresta. Este deveria ter hábitos e comportamentos de sertanejo, ou seja, caça, pesca e coleta (produção para subsistência). Porém, o caboclo não podia ter pele clara, a ele se atribuía uma cor mais ou menos escura.

${ }^{2}$ Foge aos objetivos desse trabalho, analisar e demonstrar as relações de encontro e desencontro, de contato (sobreposição) e alteridade, entre caboclos e migrantes gaúchos e catarinenses, que mais tarde ocuparam o Sudoeste do Paraná.
} 
do Estado do Rio Grande do Sul: "cada dia entravam 10 a 20 famílias, em Francisco Beltrão, muitas delas sem o controle da CANGO (...)" (WACHOWICZ, 1985:200).

De acordo com Abramovay (1981:29), o município de Francisco Beltrão tinha uma economia baseada na produção agropecuária até a década de 1950. Trata-se de uma economia praticamente voltada para a subsistência, o que ele chamou de "economia cabocla". As relações do caboclo com a cidade neste momento histórico eram "incipientes". O caboclo apenas vendia um pequeno excedente da produção agrícola (milho, feijão, mandioca, etc.), além de alguns produtos derivados de caças, como peles de animais, por exemplo, e, também, a produção de porcos, através da "safra". Esses produtos eram vendidos, por vezes, no comércio dos povoados ou, até mesmo, trocados por outros produtos, tais como sal, querosene, tecidos entre outros. Além disso, a procura por estes produtos era pequena, devido ao limitado número de habitantes do território.

\section{A Ocupação Dirigida e "Efetiva" do Município de Francisco Beltrão e a Intensificação da Relação Campo-Cidade (1940 - 2000)}

Na primeira metade da década de 1950, ocorre à chegada maciça de um grande fluxo de migrantes vindos do Rio Grande do Sul e de Santa Catarina para a região Sudoeste do Paraná. Esta ocupação ocorreu sem nenhum choque com os posseiros caboclos, habitantes que até então predominavam de forma rarefeita na região. "A população explodiu de 476 famílias em 1947, subindo para 2725 em 1956” (FERES, 1990:497).

De acordo com Lazier (1998:38), neste período a CANGO ajudava os colonos migrantes, desde a compra da terra, até sua instalação, preparação da terra, sementes etc. Além disso, a Colônia ajudava os colonos com assistência técnica especializada, para que os agricultores pudessem conseguir fixar-se e produzir para sobreviver neste novo lugar.

O fluxo migratório continuava crescendo, entre as décadas de 1950 e 1960, o fluxo de migrantes era muito maior do que a capacidade de atendimento da CANGO. Para se ter noção da intensidade deste fluxo migratório, de acordo com CORRÊA (1970b:32), “a população do Sudoeste passou de 76.376 habitantes, em 1950, para 230.379 habitantes, em 1960. A taxa de crescimento populacional no Brasil, nessa 
mesma época, era de 3,12\%, a do Estado do Paraná de 7,23\% e a do Sudoeste de $12,4 \%$ ".

Segundo Padis (1981:498), no ano de 1956, o município de Francisco Beltrão já contava com 15.248 pessoas. Deste modo, acompanhando o crescimento populacional da região, as relações campo-cidade começavam a se estabelecer de maneira "intensa" e complexa.

Houve, principalmente entre 1940 e 1960 (período de chegada intensa de migrantes riograndenses e catarinenses incentivados principalmente pela CANGO), a abertura de estradas, tanto no entorno da cidade de Francisco Beltrão que se constituía, bem como em todo o interior do município.

Isso ocorria em virtude do aumento do número populacional no município e da necessidade de escoamento da produção agrícola que cresceu com a chegada destes migrantes, demandando uma maior comunicação entre campo e cidade.

Para Padis (1981:499), o afluxo espontâneo de colonos deu grande impulso ao surgimento de novas comunidades rurais, atraindo também um considerável contingente de bodegueiros, comerciantes atacadistas-expedidores e caminhoneiros, além de criar um movimentado circuito de compradores-vendedores ambulantes dentro de Francisco Beltrão. Grande parte do comércio era realizada de forma direta, entre o produtor e o bodegueiro.

Neste contexto, partir de 1940 até 1960, a população do Sudoeste do Paraná, e conseqüentemente de Francisco Beltrão, eleva-se consideravelmente, transformando o espaço geográfico. Surgem diversos atores, principalmente no campo, que dinamizam as relações entre campo e cidade no município.

A estrutura fundiária e a produção agropecuária, de certa forma, foram um condicionante para determinar a "intensidade" da relação campo-cidade neste período. Conforme o IBGE (dados do censo agrícola de 1960), verifica-se que Francisco Beltrão tinha uma produção no campo marcada pela policultura, bem como pela criação de grandes e pequenos animais (bovinos, suínos, galinhas, etc.). Por exemplo, no ano de 1960, 96,45\% dos estabelecimentos rurais cultivavam milho e 90,90\% cultivavam feijão. Este (o feijão) era usado na alimentação humana e o milho era usado para alimentar as pessoas e os animais. Ainda segundo o IBGE, em 1960, 17,34\% dos estabelecimentos rurais de Francisco Beltrão, tinham menos de 10 hectares de área, e apenas 2,26\% tinham mais que 100 hectares de área. Este sistema de cultivo, caracterizado pela presença de vários tipos de culturas agrícolas (policultura), bem 
como a criação de animais para produzir carnes, ovos, leite, fonte de tração para o trabalho, etc., num mesmo estabelecimento rural, condicionou uma certa "independência" econômica da família do camponês frente à economia da cidade.

O município de Francisco Beltrão, em 1960, segundo o censo industrial do IBGE tinha 41 estabelecimentos industriais atuando no ramo madeireiro, o que equivalia a exatamente $50 \%$ do total de estabelecimentos industriais do município. A matéria-prima para a indústria da madeira era proveniente do campo. Nesse sentido, as "madeireiras" foram o principal ramo de indústria da época que tinham uma relação "direta" com a economia do campo, no caso, com o extrativismo vegetal.

Já o comércio em 1960 se destacou, principalmente, com os estabelecimentos chamados de "secos e molhados", que vendiam desde alimentos a roupas, bem como compravam produtos agrícolas dos agricultores. De acordo com Martins (1986), no ano de 1956, o município de Francisco Beltrão tinha 53 estabelecimentos de secos e molhados, o que equivalia a $27,32 \%$ do total de estabelecimentos, ou seja, da soma de estabelecimentos industriais, comerciais e de prestação de serviços. As relações de troca entre campo e cidade, "efetivamente", começaram a se intensificar neste período.

Outro fator marcante refere-se o uso de fertilizantes na agricultura de Francisco Beltrão até 1960, praticamente não se observa a relação de compra de fertilizantes por parte dos agricultores. De acordo com o IBGE, em 1960, apenas 0,16\% dos estabelecimentos rurais usavam fertilizantes e todos usavam fertilizantes orgânicos, que eram produzidos no próprio estabelecimento (a partir de estrumes de animais principalmente).

Contudo, em 1970, já existiam 11,09\% dos estabelecimentos rurais que usavam fertilizantes e destes, 70,11\% eram adubos químicos, comprados no comércio na cidade. Em 1975, este número eleva-se para 69,64\% dos estabelecimentos com uso de adubação química e, em 1995/96, 81,83\%! Para Kautsky (1986:45), a adubação é necessária devido ao esgotamento do solo, mas submete a agricultura aos interesses do capitalismo, pois a compra dos adubos químicos constitui um encargo adicional para a agricultura que não provém da natureza, mas se revela decorrente das condições sociais existentes: "o progresso da técnica agrícola, longe de equilibrar esse prejuízo [pobreza do solo], não passa de um método aperfeiçoado de exaurir cada vez mais o solo (aumentando o déficit de nutrientes do solo), canalizando os mesmos para a cidade" (p. 189). 
Neste contexto, a compra de fertilizantes no comércio citadino, acaba por tornar o agricultor dependente do comércio da cidade e, assim, parte da renda retirada da terra (por meio do trabalho do agricultor), vai para as mãos dos comerciantes. A renda é desviada, ou seja, "canalizada” para a cidade.

Além disso, como afirma Kautsky (1986:53), não somente a aquisição de fertilizantes, mas o crédito rural por meio de empréstimos ou financiamentos destinados à agricultura, se tornou uma outra forma de submissão do campo à cidade (dos homens do campo aos homens da cidade), pois os capitalistas que vivem do juro a partir de empréstimos concedidos, diretamente aos agricultores ou indiretamente (por via de bancos), em geral, moram na cidade, então a renda do campo é drenada para a cidade.

Em 1960 (segundo o IBGE), Francisco Beltrão tinha apenas 1,36\% dos estabelecimentos rurais que havia contraído financiamento e, todos de particulares. Em $1970,10,02 \%$ dos estabelecimentos rurais receberam financiamentos e destes, $63,23 \%$ de entidades do governo. Em 1980, já eram 42,26\% dos estabelecimentos que receberam financiamentos, sendo que $93,07 \%$ de entidades do governo.

Um dos principais fatores relacionados às mudanças nas relações econômicas em Francisco Beltrão, é a transformação técnica da produção agrícola, que está transformando a própria composição da mão-de-obra ocupada no campo, bem como a composição da mão-de-obra utilizada na economia da cidade, devido a um fluxo de migração crescente e contínuo do campo para a cidade.

Para entendermos melhor esta realidade, vale destacar que, de acordo com o IBGE (a partir de dados dos censos agropecuários), Francisco Beltrão até 1960, tinha apenas 5 tratores agrícolas usados na agricultura, número que mudou para 18 em 1970, passando para 346 em 1980 e, os expressivos 430 em 1995/96!

Assim, relacionada a este considerável aumento no número de máquinas agrícolas (tratores) utilizadas na agricultura, principalmente entre o período de 1970 e 1980, houve paralelamente uma redução do percentual e do número de habitantes que residiam no campo. Em 1970, Francisco Beltrão tinha 23.394 habitantes vivendo no meio rural, que representavam $63,56 \%$ da população do município. Em 1980, este número diminuiu para 20.473 habitantes, que equivaliam a $41,99 \%$ da população total. A população urbana deste município, ao contrário do que ocorreu com a rural, aumentou nesse período, passando de 36,44\% em 1970, para 58,01\% em 1980. 
Também no período de 1991 a 2000, este processo de diminuição absoluta e relativa da população do campo com o oposto para a população da cidade (com o crescimento) tem continuado a ocorrer em Francisco Beltrão. De acordo com o IBGE, em 1991 a população rural diminuiu para 15.650 habitantes e em 2000 para 12.301 habitantes. Assim, há claramente um processo de inversão da população rural e um aumento gradativo (década a década), como demonstramos, da população urbana.

Um fator que teve forte influência neste processo de êxodo rural foi sem dúvida a mecanização da agricultura em Francisco Beltrão. Como afirma Graziano da Silva (2002b:62), a mecanização da agricultura diminui o tempo de trabalho a ser despendido na produção agrícola, o que torna "disponível” parte da mão-de-obra, antes ocupada na agricultura, para ser ocupada em outras atividades produtivas (não-agrícolas).

Neste sentido Singer (1998:22), entende que a migração do campo para a cidade ocorre devido a transformações nos meios técnicos de produção na agricultura, de um lado, e, de outro, devido à atração que a economia de determinadas cidades pode oferecer, quanto à "oferta" de emprego.

Para Martine (1994, p. 12), esse "esvaziamento" populacional do campo para a cidade ocorre (principalmente a partir dos anos de 1970) em função da terceirização rural promovida pelas indústrias do frango/ovos de Santa Catarina, ou do fumo do Rio Grande do Sul. Estas empresas compraram terras e, conseqüentemente, expulsaram trabalhadores do campo para a cidade, também influenciando o setor rural com implementação, principalmente, do cultivo da soja e fumo e, da criação de gado.

Aliado a isso, ocorre a concentração dos agricultores na produção de frango nas empresas Sadia S/A e Gralha Azul Avícola Ltda. Estas atuam intensamente no interior do município de Francisco Beltrão, mantendo assalariados em suas propriedades privadas, ou levando diariamente assalariados da cidade para o campo para trabalhar (MONDARDO, 2005). Contudo, a adentrada dessas empresas com o sistema de terceirização dos serviços e, com isso, de assalariamento de trabalhadores no campo, acarretou a saída de inúmeros agricultores-moradores do campo, que tinham propriedades no campo e que se deslocaram para a cidade, fundamentalmente, em direção aos bairros periféricos do município de Francisco Beltrão (MONDARDO, 2007).

Segundo os censos econômicos do IBGE, Francisco Beltrão, no período (1970 a 1980), aumentou de 294 para 484 estabelecimentos (entre indústrias, comércio e prestação de serviços). O número de pessoas acima de 10 anos de idade ocupadas nos 
três setores de economia tipicamente urbana (indústria, comércio e prestação de serviços) aumentou de 4.165 pessoas em 1970, para 12.347 pessoas em 1980 e, para 24.342, no ano, de 2000. Já, na produção primária o número de pessoas acima de 10 anos de idade ocupadas, diminuiu de 8.085 em 1970, para 7.122 em 1980 e para 6.075 no ano de 2000. A partir de dados dos censos demográficos de 1970 e 1980, observa-se que Francisco Beltrão tinha em 1970, 2.974 pessoas residentes na zona urbana que vieram do campo, o que equivalia a $22,17 \%$ da população urbana, mas em 1980 , esta passou para 9.461 , cerca de $33,44 \%$.

Desta forma, na relação campo-cidade neste período teria o campo o papel de gerar mão-de-obra para a cidade de Francisco Beltrão, principalmente para as indústrias que se instalaram no município, como também para a construção civil que cresceu enormemente a partir da década de 1970.

A análise da composição etária da população urbana e rural de Francisco Beltrão (a partir do censo demográfico de 2000) revela que é maior no campo o percentual de pessoas com menos de 18 anos de idade e acima de 60 anos, porém, na faixa entre 18 e 60 anos de idade, a população urbana tem maior percentual $(57,50 \%$ urbana para $54,10 \%$ rural). Neste sentido, ao que tudo indica está ocorrendo uma saída - do campo para a cidade -, das pessoas com idade principal de trabalho (entre 18 e 60 anos de idade). Segundo Camarano \& Abramovay (1999:4), são cada vez mais jovens os que têm deixado o campo, em função principalmente da busca de trabalho e estudos que o campo não os oferece atualmente.

Para Kautsky (1986:245), saem do campo primeiramente, as pessoas mais jovens, com idade para enfrentar o mercado de trabalho nas cidades. Isto indica que a reprodução econômica e social destes "ex-agricultores" pode estar comprometida no campo e na cidade. O mercado de trabalho da cidade tem sido uma alternativa "forçada" - na maioria das vezes relacionada à ação dos grandes proprietários de terras - para a sua sobrevivência, ou ainda para atender aos sonhos e vontades de vida melhor.

Segundo Kautsky (1986:247), determinados ramos da indústria têm com a agricultura uma relação que caracteriza a expansão do grande capital para suas áreas de dominação. Isso se dá, por exemplo, quando um ramo industrial utiliza matéria-prima ou realiza um estágio de produção no campo, como acontece com os laticínios, que têm "contratos" de compra e venda com os produtores de leite.

Em Francisco Beltrão, segundo dados da SEAB-PR - Secretaria Estadual da Agricultura e do Abastecimento -, pode-se constatar que existe uma relação entre 
produtores rurais (de leite) com laticínios do Sudoeste Paranaense, o que está vinculado ao aumento da média de leite vendido pelos produtores em Francisco Beltrão, passando de 21.870,71 litros por produtor em 2002, para 40.084,63 em 2003. Estas empresas traçam suas áreas de dominação, suas redes de produção e de comercialização agropecuária. A partir disso, os produtores de leite de Francisco Beltrão (em sua maioria), também se tornaram "súditos" dos laticínios, como Kautsky apontou ter ocorrido na Suíça, em relação à companhia Nestlé ${ }^{3}$.

Graziano da Silva (2003:24) entende que as indústrias que trabalham no sistema de "integração" com produtores rurais, constituem uma forma de exploração do capital industrial sobre o produtor rural integrado. Ele cita o exemplo das empresas que trabalham com a produção e processamento de carne de aves, especialmente no sul do país.

De acordo com a SEAB-PR, Francisco Beltrão tem empresas que industrializam a carne de aves (principalmente de frangos), que são criados em propriedades rurais, onde o produtor se compromete com a construção do local em que são criadas as aves (o aviário, o edifício) e com o fornecimento da mão-de-obra, enquanto a indústria fornece as aves (jovens) e os insumos (rações, remédios, etc.).

Para Graziano da Silva (2003:31), a estratégia das empresas que trabalham no sistema de integração com produtores rurais, consiste em fazer com que o avicultor pense estar trabalhando em parceria com a empresa "integradora" e não trabalhando para a empresa, como acontece na realidade (a empresa paga quanto ela "quer"). Em outras palavras, as empresas tentam de toda forma alienar "enganando" os produtores rurais integrados, fazendo-lhes pensar que estes ganham com a produção agropecuária integrada proporcionalmente ao ganho da empresa, e evitar que eles reconheçam assim, sua relação de subordinação frente à indústria.

A relação de comercialização da produção agrícola é uma das formas das relações campo-cidade, que têm suas especificidades e que, assim como o sistema de integração entre indústria e produtor rural, pode contribuir para a reprodução social e econômica, tanto do produtor rural quanto do comerciante que, em geral, reside na cidade.

\footnotetext{
${ }^{3}$ Ao realizar seus estudos sobre a atuação dos laticínios em alguns países da Europa, no final do século XIX, este autor alertou para a capacidade de dominação dessas empresas sobre os produtores rurais: "são 180 aldeias que perderam sua independência econômica para se tornarem súditas da Companhia Nestlé. Extrinsecamente, os habitantes dessas aldeias ainda são proprietários de suas terras, mas intrinsecamente já não mais constituem camponeses livres" (KAUTSKY, 1986:247).
} 
De acordo com Corrêa (1989:58), o processo de comercialização da produção rural é muito complexo, mais de forma geral, “(...) a cidade impõe ao campo um preço inferior aos praticados no meio urbano". Sendo assim, de acordo com os dados do IBGE, observa-se que em Francisco Beltrão houve, no período de 1970 a 1980, um aumento no número de estabelecimentos de comércio atacadista do ramo agropecuário (cereais em geral). No ano de 1980, este tipo de comércio já contribuía com 17,77\% da receita de todo o comércio beltronense.

Neste aspecto, para Marx (2003b:91), no capital comercial a extração da maisvalia surge devido ao comerciante não pagar ao capitalista industrial toda a mais-valia extraída do trabalho do proletariado industrial. Existe assim, uma divisão da mais-valia entre o industrial e o comerciante. Se analisarmos a relação entre os comerciantes da produção agrícola a partir desta concepção de Marx, entenderemos que os comerciantes "tomam" parte da renda dos produtores rurais.

Uma das principais "faces" das relações campo-cidade, a ser considerada em Francisco Beltrão, é a existência de proprietários de estabelecimentos rurais que residem na cidade, transferindo assim, a renda da produção agropecuária para a cidade. De acordo com os censos agropecuários do IBGE, Francisco Beltrão em 1980, tinha 5,52\% dos estabelecimentos rurais (com $11,89 \%$ da área total), em que os proprietários residiam na cidade e em 1995/96, este número eleva-se para 10,06\% dos estabelecimentos e para $22,06 \%$ da área total.

Assim, em 1995/96, 22,06\% da área agrícola (do campo), tinha como proprietários pessoas que não residiam nas propriedades rurais, mas na cidade. Neste sentido, apoiando-se em Corrêa (1989:44) podemos considerar que:

A drenagem da renda fundiária pela cidade constitui-se em muitas áreas um importante aspecto da vida social, econômico e política. A cidade constitui-se nesses casos, um lugar de residência de proprietários rurais absenteístas [que não comparece, vive fora, nesse caso, na cidade] e este fato pode assumir enorme importância.

Segundo Graziano da Silva (2002b:56), nas últimas décadas do século XX (principalmente a partir dos anos de 1990), passaram a ocorrer algumas transformações no campo, que fariam jus à denominação de novo rural brasileiro. Surgem as ORNAs ocupações rurais não-agrícolas, tais como pedreiros, empregados domésticos, motoristas, entre outros, empregadas por pessoas que residem no meio rural. Paralelamente há um crescimento das atividades não-agrícolas no meio rural 
(geralmente ligadas ao lazer, como os hotéis-fazenda, locais para recreação, associações, pesque-pagues, etc). Somando-se a tais mudanças, Graziano da Silva chama a atenção para o grande número de famílias ocupadas em tempo parcial na agricultura, ocupando outra parte do tempo em atividades não-agrícolas. Este autor as chama de famílias pluriativas.

Tais transformações, que caracterizariam o que Graziano da Silva (2002b:81) chama de "novo rural" (atividades rurais não-agrícolas, pluriatividade, etc.), estão acontecendo em Francisco Beltrão. Seria neste ponto, uma "nova face" das relações campo-cidade, que poderíamos chamar por ora de "urbanização do meio rural", ou melhor, "rurbanização".

Atualmente, existem no município de Francisco Beltrão, e, sobretudo no campo, vários parques, recantos, cachoeiras, enfim, áreas de lazer e recreação que se especializam e se materializam de forma que complexificam as relações campo cidade e tornam essas relações mais "intensas".

Um outro aspecto das relações campo-cidade é a contribuição que o êxodo rural está tendo para o crescimento da cidade de Francisco Beltrão, no que se refere principalmente ao aumento da população e à expansão dos espaços físicos da mesma. Isso se materializa em decorrência do surgimento de "novas" áreas residenciais, geralmente localizadas no "limite" urbano e rural. Muitas famílias que vêem morar nestes novos espaços na cidade - denominados de bairros periféricos -, são oriundas, sobretudo, da zona rural do município.

\section{Considerações Finais}

As relações campo-cidade, partindo-se do fator político e econômico que aqui enfocamos, levam-nos a compreender que grandes empresas como lacticínios, cerealistas, "agroindústrias integradoras" criam suas redes de atuação, redes de escoamento da produção agrícola, redes de integração da indústria com o produtor rural etc; criam seus territórios, que são as "prisões do espaço", como escreve Raffestin (1993:204). “A rede faz e desfaz as prisões do espaço, tornando território: tanto libera como aprisiona. É o porquê de ela ser o ‘instrumento’ por excelência do poder”.

Neste sentido, estas redes e suas tramas demonstram como são complexas as relações entre campo-cidade e que, uma vez compreendidas, poderão "revelar" a lógica dialética - no sentido que Lefébvre (1995) utiliza - do processo onde o homem em suas 
relações sociais (relações de trabalho, de trocas comerciais, políticas, culturais etc.) (trans)forma o espaço onde vive e materializa formas (que expressam conteúdos, sentidos e significados). São relações entre campo e cidade, entre espaços que se articulam, que se complementam, que se imbricam para reproduzir o mesmo movimento: a vida.

A justaposição, portanto, entre interesses de homens e mulheres do campo e da cidade, revela a trama dos poderes em que são produzidos (e constantemente) reproduzidos formando espacialidades "distintas" (mas não dicotômicas) entre campo e cidade. O campo e cidade devem ser apreendidos como espaços que expressam o(s) mesmo(s) movimento(s), isto é, a reprodução da sociedade sobre e com uma base material. Assim, campo e cidade representam a materialização dos modos de vida e de (re)produção dos homens e mulheres que vivem do/no campo da/na cidade.

Dessa maneira, compreender as relações campo-cidade é uma forma de analisar a complexidade da atividade social sobre o espaço geográfico. É umas das maneiras de se apreender como os homens e mulheres produzem suas idéias, materializam seus interesses no espaço, produzindo e sendo produzidos pelos espaços de morada e de trabalho, de lazer e de consumo. São espaços que (trans)formam homens e mulheres em constante movimento. São espaços que demonstram a mutação entre o homem e suas realizações materializadas em formas-conteúdos, no campo e na cidade, entre o campocidade. 


\section{Referências}

ABRAMOVAY, Ricardo. Transformações na vida camponesa: o sudoeste paranaense. São Paulo, 1981. Dissertação (Mestrado em Ciências Sociais) USP.

ALENTEJANO P. R. R. Reforma Agrária, território e desenvolvimento no Rio de Janeiro. Rio de Janeiro, 2003. Tese (Doutorado em Geografia) - CPDA - Universidade Federal Rural do Rio de Janeiro, Rio de Janeiro.

BAGLI, P. Novas territorializações e territorialidades: o rural e o urbano em questão no Pontal do Paranapanema. Presidente Prudente, 2004. Relatório de pesquisa (FAPESP).

CAMARANO, Ana Amélia; ABRAMOVAY, Ricardo. Exodo rural, envelhecimento e masculinização no Brasil: panorama dos últimos 50 anos. IPEA: Rio de Janeiro, 1999. (Texto para Discussão $n^{\circ} 621$ )

CORRÊA, Roberto L. A rede urbana. São Paulo: Ática, 1989.

. Região e organização espacial. 6. ed. São Paulo: Ática, 1998.

. O espaço urbano. 4. ed. são Paulo: Ática, 1999.

. O Sudoeste paranaense antes da colonização. Revista Brasileira de Geografia, Rio de Janeiro, n.1, p.87-98, jan./mar. 1970a.

. Cidade e região no Sudoeste Paranaense. Revista Brasileira de Geografia, Rio de Janeiro, v. 32, n. 2, p. 3-155, 1970 b.

FERES, João Bosco. Propriedade da Terra. Opressão e Miséria - O meio Rural na História Social do Brasil. Amsterdam: CEDLA, 1990.

GRAZIANO DA SILVA, José. (coord.). Estrutura agrária e produção de subsistência na agricultura brasileira. 2. ed. São Paulo: Hucitec, 1980.

. A nova dinâmica da agricultura brasileira. Campinas (SP): Ed. da UNICAMP, 1996.

. O desenvolvimento do capitalismo no campo brasileiro e a reforma agrária. In: STÉDILE, João P. (Org.). A questão agrária hoje. Porto Alegre (RS): Ed. da UFRGS, 2002a.

O novo rural brasileiro. 2. ed. Campinas (SP): UNICAMP. IE, 2002b. (Coleção Pesquisas, 1).

. Tecnologia e agricultura familiar. 2. ed. Porto Alegre (RS): Ed. da UFRGS, 2003. 
IBGE. Censo industrial de 1960: Paraná, Santa Catarina e Rio Grande do Sul. Rio de Janeiro: IBGE, 1966. v. 3 - Tomo 7.

. Censo comercial e dos serviços de 1960: Paraná, Santa Catarina e Rio Grande do Sul. Rio de Janeiro: IBGE, 1967. v. 6 - Tomo 10.

. Censo agrícola de 1960: Paraná e Santa Catarina. Rio de Janeiro: IBGE, 1967. v. 2 - Tomo 12.

. Censo demográfico - Paraná - 1970. Rio de Janeiro: IBGE, 1973. v. 1 - Tomo 19.

. Censo industrial - Paraná - 1970. Rio de Janeiro: IBGE, 1973. v. 4 - Tomo 19. . Censo agropecuário - Paraná - 1970. Rio de Janeiro: IBGE, 1975. v. 3 - Tomo 19.

. Censo comercial-Paraná - 1970. Rio de Janeiro: IBGE, 1975. v. 6 - Tomo 19.

. Censo dos serviços - Paraná - 1970. Rio de Janeiro: IBGE, 1975. v. 7 - Tomo 19.

. Censo agropecuário - Paraná - 1975. Rio de Janeiro: IBGE, 1979. v. 1 - Tomo 18.

. Censo agropecuário - Paraná - 1980. Rio de Janeiro: IBGE, 1983. v. 2 - Tomo 3.

. Censo demográfico - Paraná - 1980. Rio de Janeiro: IBGE, 1983. v. 1 - T. 4, 5 e 6 .

. Censo comercial-Paraná - 1980. Rio de Janeiro: IBGE, 1984. v. 4 - No 20.

. Censo dos serviços - Paraná - 1980. Rio de Janeiro: IBGE, 1984. v. 5 - No 20.

. Censo industrial - Paraná - 1980. Rio de Janeiro: IBGE, 1984. v. 3 - No 20.

. Pesquisa nacional por amostra de domicílios - PNAD: Paraná. Rio de Janeiro:

IBGE, 1984. v. 6.

. Censo agropecuário - Paraná - 1985. Rio de Janeiro: IBGE, 1991. № 22.

. Censos econômicos de 1985 - municípios: Região Sul - Indústria, Comércio e

Serviços. Rio de Janeiro: IBGE, 1991. v. 4.

. Censo demográfico - Paraná - 1991. Rio de Janeiro: IBGE, 1996. № 20.

. Censo agropecuário - Paraná - 1995/96. Rio de Janeiro: IBGE, 1998. № 20.

(CD ROM).

. Censo demográfico - Paraná - 2000. Rio de Janeiro: IBGE, 2001. (CD ROM).

. Censo demográfico - Paraná - 2000. Rio de Janeiro: IBGE, 2002. (CD ROM).

. Censo demográfico - Paraná - 1960. Rio de Janeiro: IBGE, s/d. v. 1. Tomo 14. 
Base Cartográfica do Paraná - 2005.

LAZIER, Hermógenes. Análise Histórica da posse da terra no Sudoeste Paranaense. Editora Grafit, 3ª ed. Francisco Beltrão - PR, 1998.

LEFEBVRE, Henri. $O$ direito à cidade. 3. ed. Tradução de Rubens E. Frias. São Paulo: Centauro, 2004. Lógica formal e lógica dialética. Rio de Janeiro: Civilização Brasileira, 1995.

KAUTSKY, Karl. A questão agrária. Tradução de Otto Erich W. Mass. São Paulo: Nova Cultural, 1986.

MARTINE, George. A Redistribuição Espacial da População Brasileira Durante a Década de 80. Janeiro de 1994. Texto para Discussão nº 421.

MARX, Karl e ENGELS, Friedrich. A ideologia alemã. Tradução de Luiz C. Costa. São Paulo: Martins Fontes, 1998.

MARX, Karl. O capital: crítica da economia política - o processo de produção do capital. Tradução de Reginaldo Sant'Anna. 18. ed. Rio de Janeiro: Civilização Brasileira, 2002. Livro I, v. 2.

O capital: crítica da economia política - o processo de produção do capital.

Tradução de Reginaldo Sant'Anna. 21. ed. Rio de Janeiro: Civilização Brasileira, 2003a. Livro I, v. 1.

O capital: crítica da economia política - o processo de circulação do capital.

Tradução Reginaldo Sant'Anna. 9. ed. Rio de Janeiro: Civilização Brasileira, 2003b. Livro II.

MONDARDO, Marcos L. As migrações e as transformações territoriais na Comunidade Barra do Rio Tuna - Francisco Beltrão - PR. Francisco Beltrão/PR, 2005. Monografia (Bacharelado em Geografia)-Unioeste, Francisco Beltrão, 2005.

. Uma Caracterização Geral do Processo de Urbanização do Sudoeste do Paraná Brasil. Scripta Nova. Revista Electrónica de Geografía y Ciencias sociales. Barcelona: Universidade de Barcelona, 15 de maio de 2007, vol. XI, núm. 239. Disponível em: $<$ http://www.ub.es/geocrit/sn/sn-239.htm>

RAFFESTIN, Claude. Por uma geografia do poder. Tradução de Maria C. França. São Paulo: Ática, 1993.

SANTOS, Milton. Técnica, espaço, tempo. Globalização e Meio Técnico-Científico Informacional. 3 ed. Hucitec: São Paulo, 1997. . A Natureza do Espaço. 4 ed. São Paulo: Edusp, 2004. 
PADIS, Pedro Calil. Formação de uma Economia Periférica: O caso do Paraná. São Paulo: HUCITEC; Curitiba, 1981.

SILVA, A. F. da. A relação cidade-campo: como analisá-la? Natal: Imagem, 1998.

SINGER, Paul. Dinâmica populacional e desenvolvimento. 3. ed. São Paulo: Hucitec, 1980.

Economia política e urbanização. 14. ed. São Paulo: Contexto, 1998.

SOUZA. Itamar de. Migrações Internas no Brasil. Rio de Janeiro-Petrópolis: Vozes, 1980.

STECA, Lucinéia Cunha; FLORES, Mariléia Dias. História do Paraná: Do século XVI à década de 1950. Londrina: ed. UEL, 2002.

WACHOWICZ, Ruy C. Paraná, Sudoeste: ocupação e colonização. $2^{\mathrm{a}}$ ed. Editora Vicentina: Curitiba, 1987. . História do Paraná. $6^{\mathrm{a}}$ ed. Editora Gráfica Vicentina. Curitiba, 1985.

WANDERLEY, M. de N. B. A ruralidade no Brasil Moderno. Por um pacto social pelo desenvolvimento rural. In: GIARRACCA, N. (Org) Una nueva ruralidad en América Latina? Buenos Aires: CLASCO/ASDI, 2001. p. 31-44. 